\title{
TGF- $\beta$ receptor II in epithelia versus mesenchyme plays distinct roles in the developing lung
}

\author{
H. Chen*, F. Zhuang" ${ }^{\#}$, Y-H. Liü ${ }^{\#}$, B. Xu*, P. del Moral*, W. Deng*, Y. Chai ${ }^{*}$, M. Kolb+, \\ J. Gauldie ${ }^{+}$, D. Warburton*, H.L. Moses ${ }^{\S}$ and W. Shi* ${ }^{\star *}$
}

ABSTRACT: Transforming growth factor (TGF) $\beta$ signalling plays important roles in regulating lung development. However, the specific regulatory functions of TGF- $\beta$ signalling in developing lung epithelial versus mesenchymal cells are still unknown.

By immunostaining, the expression pattern of the TGF- $\beta$ type II receptor (TRRII) was first determined in the developing mouse lung. The functions of $T \beta R I I$ in developing lung were then

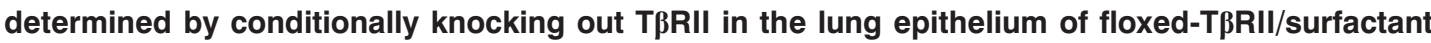
protein C-reverse tetracycline transactivator/TetO-Cre mice versus mesenchyme of floxed-TßRII/ Dermo1-Cre mice.

$T \beta R$ II was expressed only in distal airway epithelium at early gestation (embryonic day (E)11.5), but in both airway epithelium and mesenchyme from mid-gestation (E14.5) to post-natal day 14. Abrogation of TRRII in mouse lung epithelium resulted in retardation of post-natal lung alveolarisation, with markedly decreased type I alveolar epithelial cells, while no abnormality in prenatal lung development was observed. In contrast, blockade of T $\beta R$ II in mesoderm-derived tissues, including lung mesenchyme, resulted in mildly abnormal lung branching and reduced cell proliferation after mid-gestation, accompanied by multiple defects in other organs, including diaphragmatic hernia. The primary lung branching defect was verified in embryonic lung explant culture.

The novel findings of the present study suggest that transforming growth factor- $\beta$ type II receptor-mediated transforming growth factor- $\beta$ signalling plays distinct roles in lung epithelium versus mesenchyme to differentially control specific stages of lung development.

KEYWORDS: Lung alveolarisation, lung branching morphogenesis, transforming growth factor- $\beta$, transforming growth factor- $\beta$ type II receptor

ung development is initiated by the formation of a pair of primary epithelial buds that evaginate from the laryngo-tracheal groove in the ventral surface of the primitive foregut endoderm into the surrounding splanchnic mesenchyme $[1,2]$. The respiratory tree then develops by branching morphogenesis, in which reiterated outgrowth, elongation and subdivision of epithelial buds occurs, followed later by alveolarisation to form a large gas-exchange surface $[3,4]$. Disruption of normal lung developmental processes can result in neonatal respiratory failure or distress if lung formation is severely affected, or susceptibility to lung diseases during later life if milder changes occur in the developing lung [5].

Since the lung developmental process is quite well conserved, mouse lung development is an ideal model for studying the mechanism of lung organogenesis and congenital respiratory diseases in humans. In mouse, lung development begins at embryonic day (E)9.5, and is divided histologically into pseudoglandular stage (E9.5E16.5), canalicular stage (E16.6-E17.4), saccular stage (E17.5-post-natal day (P)5) and alveolar stage (P5-P30) [1]. During lung development, epithelial-mesenchymal interaction plays a critical role in guiding early lung branching morphogenesis and, later, alveogenesis, which is regulated by many growth factors, including members of the transforming growth factor (TGF)- $\beta$ superfamily [6]

TGF- $\beta 1,-\beta 2$ and $-\beta 3$ ligands are closely related members of the TGF- $\beta$ superfamily that have differential expression patterns in vivo and biological activities in vitro. TGF- $\beta$ ligands bind to heteromeric complexes of TGF- $\beta$ serine/threonine
AFFILIATIONS

*Developmental Biology Program, Children's Hospital Los Angeles, \#Dept of Ophthalmology, Keck School of Medicine, University of Southern California,

"The Center of Craniofacial Molecular Biology, University of Southern California School of Dentistry, Los Angeles, CA, and ${ }^{\S}$ Vanderbilt-Ingram Cancer Center, Nashville, TN, USA

+Dept of Medicine, Pathology and Molecular Medicine, McMaster University, Hamilton, ON, Canada

\section{CORRESPONDENCE}

W. Shi

Developmental Biology Program

Dept of Surgery

Childrens Hospital Los Angeles

4650 Sunset Blvd

MS 35

Los Angeles

CA 90027

USA

Fax: 13233613613

E-mail: wshi@chla.usc.edu

Received:

December 062007

Accepted after revision:

February 212008

\section{SUPPORT STATEMENT}

$W$. Shi received support from the National Institutes of Health (NIH), grant HL68597. D. Warburton received NIH grants HL60231, HL44060, HL44977 and HL75773, and support from the Webb Foundation (Los Angeles, CA, USA).

STATEMENT OF INTEREST None declared.

European Respiratory Journal Print ISSN 0903-1936 Online ISSN 1399-3003 
kinase type I and type II receptors (T $\beta R I$ and T $\beta R I I$, respectively) $[7,8]$. Upon ligand-induced aggregation of the receptors, constitutively activated T $\beta$ RII kinase phosphorylates and activates the T $\beta R I$, which subsequently recognises and phosphorylates receptor-bound TGF- $\beta$-specific Smad proteins (Smad2 and Smad3) on the carboxy terminal SSXS motif. These phosphorylated Smads dissociate from the receptors, form complexes with a common partner, Smad4, translocate into the nucleus, directly or indirectly bind to the TGF- $\beta$ responsive element and act as transcriptional co-modulators to induce or repress TGF- $\beta$ target gene expression [9]. In addition, Smad-independent signalling pathways are also activated through the same receptors [10]. T $\beta$ RII is the only type II receptor specific for TGF- $\beta$.

TGF- $\beta$ signalling plays a key role in normal lung development. Null mutations of TGF- $\beta$ s result in either abnormal foetal lung development or excessive inflammation in the post-natal lung [11-14], indicating that TGF- $\beta$ signalling is essential for normal lung formation and function. In addition, abnormal lung branching morphogenesis was observed in an intact embryonic lung explant culture system when exogenous TGF- $\beta 1$ was added into the culture medium [15]. Furthermore, overexpression of TGF- $\beta 1$ driven by a $3.7 \mathrm{~kb}$ human surfactant protein $(S P) C$ promoter in lung epithelium of transgenic mice exhibited a hypoplastic lung phenotype [16], suggesting that appropriate TGF- $\beta$ signalling at the right place and right time is essential for normal lung organogenesis. Moreover, changes in endogenous TGF- $\beta$ signalling have been speculated to mediate delay in male foetal lung maturation caused by elevated androgens $[17,18]$. However, the lung is a complex organ, so global alteration of TGF- $\beta$ ligand level may affect TGF- $\beta$ signalling activities differently in either lung epithelium or mesenchyme, or indeed both, by changing autocrine and/or paracrine signalling activities, which may be difficult to distinguish. Conventional knockout of the critical T $\beta R I I$ results in early embryonic lethality, due to defects in haematopoiesis and vasculogenesis prior to lung formation [19]. In the present study, endogenous T $\beta$ RII-mediated TGF- $\beta$ signalling was selectively abrogated in either lung epithelial cells or mesenchymal cells of the developing mouse lung using Cre/loxP conditional knockout approaches, and it was found that TGF- $\beta$ signalling plays important and distinct roles in lung epithelial versus mesenchymal cells to differentially control normal mouse lung development at different developmental stages.

\section{MATERIALS AND METHODS}

\section{Mouse strains and breeding}

Floxed T $\beta R I I\left(T \beta R I I^{\mathrm{fx} / \mathrm{fx}}\right)$ mice were generated in the laboratory of H.L. Moses, as previously described [20]. In $T \beta R I I^{\mathrm{fx} / \mathrm{fx}}$, exon 2 of the TRRII gene was flanked with two loxP DNA elements. Deletion of exon 2 causes frameshift and eliminates functional T $\beta R I I$ protein expression. Inducible lung epithelial-specific Cre transgenic mice (SPC-reverse tetracycline transactivator (rtTA)/ TetO-Cre) were generated and provided by J.A. Whitsett [21]. Mesoderm-specific Dermo1-Cre heterozygous knock-in mice $\left(\right.$ Dermo1-Cre $\left.{ }^{+/-}\right)$were generated and kindly provided by D.M. Ornitz [22].

Timed mating between T $\beta R I I^{\mathrm{fx} / \mathrm{fx}}$ and T $\beta R I I^{\mathrm{fx} /+} / S P C-r t T A / T e t O-$ Cre mice generated lung epithelial-specific T $\beta R I I$ conditional knockout (Ep-CKO) mice (T $\left.\beta R I I^{\mathrm{fx} / \mathrm{fx}} / \mathrm{SPC}-r t \mathrm{TA} / \mathrm{TetO}-\mathrm{Cre}\right)$, heterozygous T $\beta R I I$ knockout mice $\left(T \beta R I I^{\mathrm{fx} /+} / S P C-r t T A / T e t O-\right.$ Cre) and control mice (T $\beta R I I^{\mathrm{fx} / \mathrm{fx}}, T \beta R I I^{\mathrm{fx} /+}, \mathrm{T} \beta R I I^{\mathrm{fx} / \mathrm{fx}} / S P C-r t T A$, T $\beta R I I^{\mathrm{fx} / \mathrm{fx}} /$ TetO-Cre, T $\beta R I I^{\mathrm{fx} /+} /$ SPC-rtTA or T $\beta R I^{\mathrm{fx} /+} /$ TetO-Cre) when the inducing agent doxycycline (Dox) was present. Normal lung development in the control mice was the same as in wildtype mice $\left(T \beta R I I^{+/+}\right)$. Administration of Dox started from either early gestation stage E6.5 or P30 to the end-point of the experiment, by feeding the pregnant or young mice with $625 \mathrm{mg} \cdot \mathrm{kg}^{-1}$ Dox in food (TestDiet, Richmond, IN, USA) and $0.5 \mathrm{mg} \cdot \mathrm{mL}^{-1}$ in drinking water (Sigma-Aldrich Co., St Louis, MO, USA).

Timed mating between T $\beta R I I^{\mathrm{fx} / \mathrm{fx}}$ and T $\beta R I I^{\mathrm{fx} /+} /$ Dermo1-Cre $^{+}$ mice generated mesoderm-specific T $\beta R I I$ conditional knockout (Me-CKO) mice (T $\beta R I I^{\mathrm{fx} / \mathrm{fx}} /$ Dermo1-Cre $\left.{ }^{+}\right)$, heterozygous T $\beta R I I$ knockout mice $\left(T \beta R I I^{\mathrm{fx} /+} /\right.$ Dermo1-Cre $\left.^{+}\right)$and control mice $\left(T \beta R I I^{\mathrm{fx} /+}\right.$ or $\left.\mathrm{T} \beta R I I^{\mathrm{fx} / \mathrm{fx}}\right)$. All mice were bred in the C57BL/6 strain background and genotyped by genomic DNA PCR. Mice used in the study were housed in pathogen-free conditions according to the protocol approved by the Institutional Animal Care and Use Committee at the Saban Research Institute of Childrens Hospital (Los Angeles, CA, USA).

\section{Histology and morphometric analysis}

Lung was fixed with $4 \%$ buffered paraformaldehyde at $4{ }^{\circ} \mathrm{C}$ overnight, dehydrated and embedded in paraffin. Sections $5 \mu \mathrm{m}$ thick were stained with haematoxylin and eosin (HE), as previously described [23]. Elastin was stained using Hart's resorcin-fuchsin solution, and counterstained with $0.5 \%$ tartrazine. For morphometric analysis, five sections from the same lobes of each sample were randomly chosen at $\sim 250-\mu \mathrm{m}$ intervals and stained with HE. The mean linear intercept (MLI) was then measured according to established methods [23-25]. Briefly, an image of each section examined was digitally captured at $40 \times$ magnification. The horizontal and vertical lines at $\sim 0.9$-mm intervals within a rectangular grid were then used to count alveolar surface intersections using ImagePro software. The MLI was then calculated as the sum of the length of all counting lines divided by the total number of counted intercepts of alveolar septa. Results were analysed with unpaired t-tests to compare the differences between mean values, and considered significant if $\mathrm{p}<0.05$. In order to avoid the sex differences in foetal lung maturation [26], this quantitative comparison was performed among foetuses with the same sex at each time-point.

\section{Immunohistochemistry}

The following antibodies were used in the present study: T $\beta$ RII and aquaporin (AQP)5 goat polyclonal antibodies from Santa Cruz Biotechnology, Inc. (Santa Cruz, CA, USA); $\alpha$-smooth muscle actin (SMA) and laminin antibodies from SigmaAldrich Co.; and SPC antibody from Seven Hills Bioreagents (Cincinnati, OH, USA).

Immunohistochemical staining was performed using the HistoStain kit from Zymed Laboratories, Inc. (South San Francisco, CA, USA), according to the manufacturer's instructions. Either 3-amino-9-ethylcarbazole or 3,3'-diaminobenzidine was used as the chromogenic substrate.

\section{Cell proliferation and apoptosis}

Cell proliferation was analysed by proliferating cell nuclear antigen (PCNA) staining using a PCNA staining kit from Zymed Laboratories, Inc., and apoptosis was evaluated by 

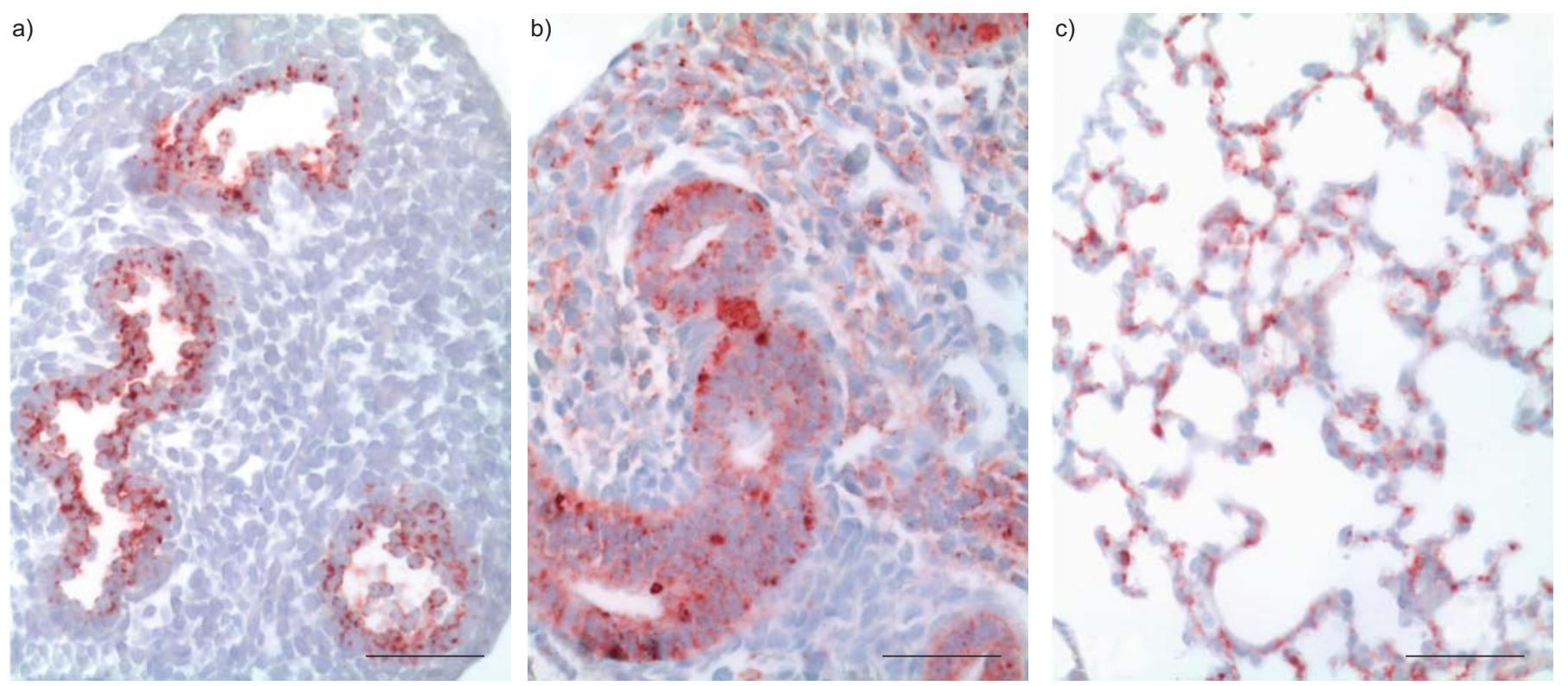

FIGURE 1. Transforming growth factor- $\beta$ type II receptor (TßRII) protein expression in the developing mouse lung, as detected by immunohistochemistry. a) At early

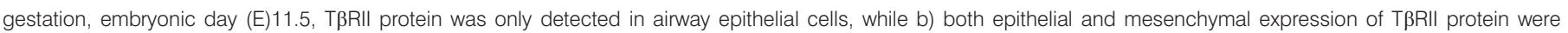

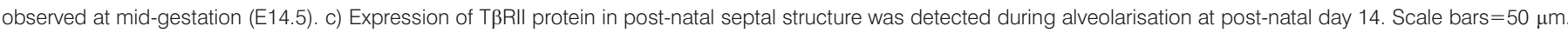

terminal deoxynucleotidyl transferase-mediated deoxyuridine triphosphate nick-end labelling (TUNEL) staining using an ApopTag kit (Millipore, Billerica, MA, USA), as previously described [27].

\section{Western blot}

Detection of lung tissue proteins has been previously described [28]. Briefly, fresh lung tissues were lysed on ice in radioimmuno precipitation assay buffer containing $1 \mathrm{mM}$ phenylmethyl sulphonyl fluoride, protease inhibitor cocktail (Roche Diagnostics, Basel, Switzerland) and $1 \mathrm{mM}$ sodium orthovanadate. Protein concentration was measured by the Bradford method using the reagents purchased from Bio-Rad Laboratories (Hercules, CA, USA). Equal amounts $(40 \mu \mathrm{g})$ of total tissue lysate proteins were separated in NuPAGE 4 4-12\% gradient SDS-PAGE gels using a MOPS buffering system (Invitrogen, Carlsbad, CA, USA). After protein was transferred onto polyvinylidene difluoride membrane, proteins of interest were detected by specific antibodies. Antibodies for cyclin-dependent kinase $(\mathrm{CDK}) 2, \beta$-actin and T $\beta$ RII were purchased from Santa Cruz Biotechnology, Inc., and anti-glyceraldehyde-3-phosphate dehydrogenase was obtained from Research Diagnostics, Inc. (Flanders, NJ, USA).

\section{Data presentation and statistical analysis}

At least three pairs of T $\beta$ RII conditional knockout (CKO) and normal control littermate mice from different dams were analysed in each experimental subgroup. All quantitative data a)

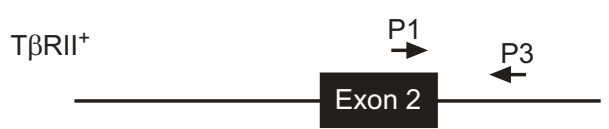

$T \beta R I I^{f x}$

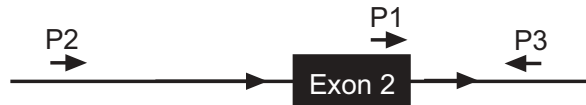

$\mathrm{T} \beta \mathrm{R} I I^{\mathrm{del}}$

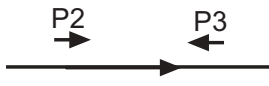

b)

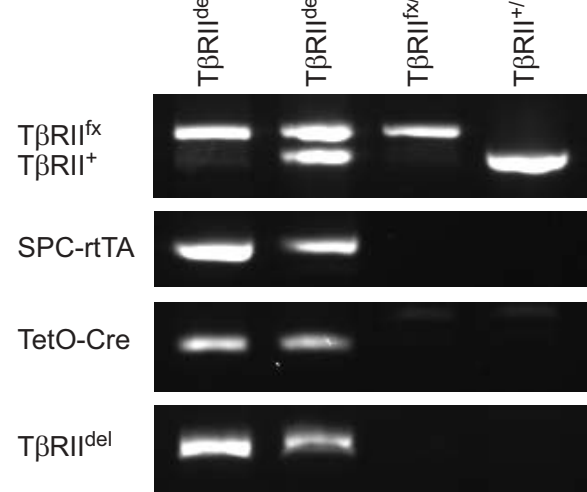

c)
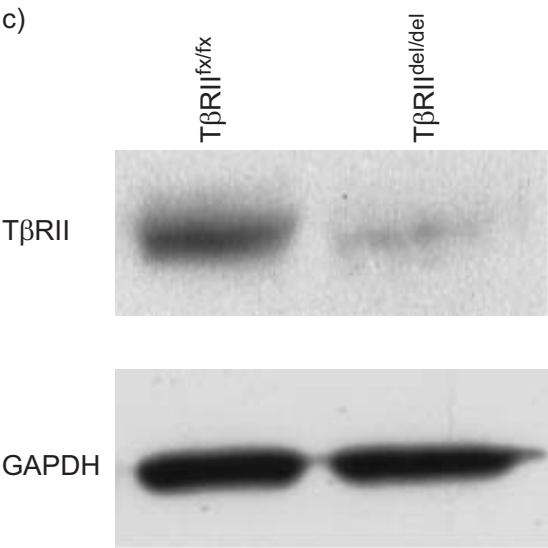

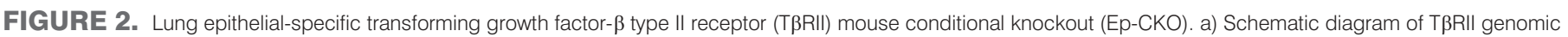
structure in the genetically manipulated mice. The positions of genotyping PCR primers are indicated (P1-P3). b) PCR genotypes of lung tissue genomic DNA. c) Significant

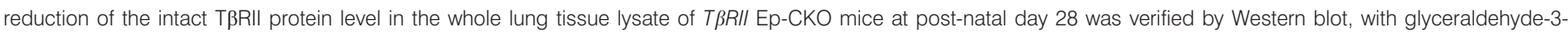

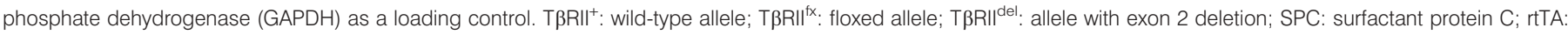
reverse tetracycline transactivator. 

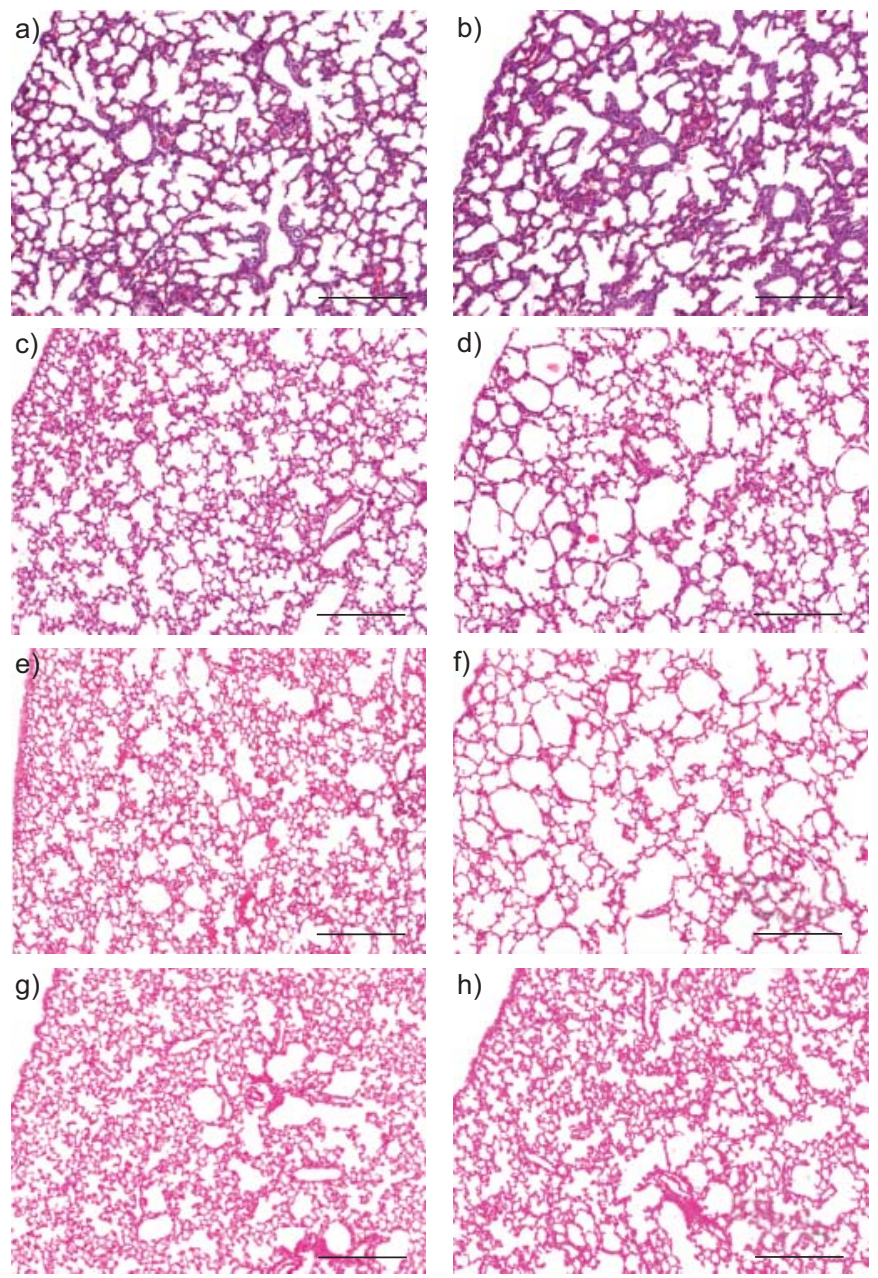

were expressed as mean $\pm \mathrm{SD}$. ANOVA and unpaired t-tests were used for comparison of statistical difference and $p$-values $<0.05$ were considered to be significant.

\section{RESULTS}

\section{Conditional abrogation of T/RII in mouse lung epithelial cells during lung development}

Mouse embryos with the conventional TRRII null mutation die before E10.5 with defects in haematopoiesis and vasculogenesis before lung development [19]. Thus, the conventional TRRII knockout mouse model is not applicable for studying T $\beta R I I$ function in lung formation, and a lung-specific conditional T $\beta R I I$ knockout mouse model using a Cre-loxP system is required for this in vivo study. In order to select cell lineagespecific Cre driver lines to abrogate T $\beta$ RII function during lung development, T $\beta$ RII protein expression at different lung developmental stages was first examined using immunohistochemistry (fig. 1). Interestingly, T $\beta$ RII was specifically expressed in distal lung airway epithelial cells at the early embryonic stage E11.5, with no detectable expression in mesenchymal cells, although both epithelial and mesenchymal cells expressed T $\beta$ RII protein later, at gestational day E14.5. T $\beta$ RII was also strongly expressed in both epithelial and mesenchymal cells in the post-natal lung during alveogenesis,

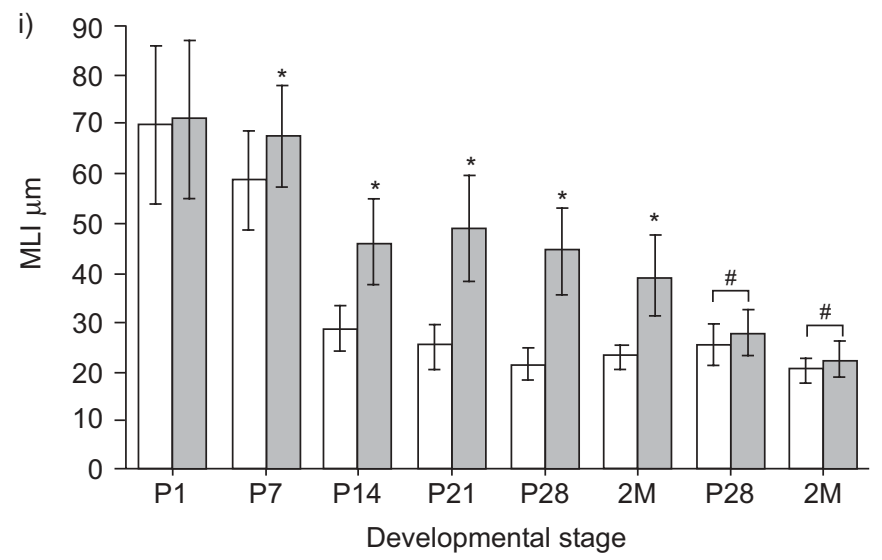

FIGURE 3. Changes in morphology and morphometric measurement of lung epithelium-specific transforming growth factor- $\beta$ type $\|$ receptor (T $\beta R I I)$ conditional knockout (Ep-CKO) mouse lungs. Haematoxylin and eosin-stained lung tissue sections from different post-natal developmental stages in normal controls (a, c and e) and $T \beta R / /$ Ep-CKO mice (b, d and f). No detectable changes in neonatal (post-natal day $(\mathrm{P}) 1$ ) lung were found in T $\beta R / / \mathrm{Ep}-\mathrm{CKO}$ mice compared with the controls (a and b). However, terminal air sacs remained larger due to reduced subdivision, a consequence of retarded growth of the secondary septal structures in T $\beta R / /$ Ep-CKO lung at P14 ( $c$ and $d$ ) and P28 (e and f). Alveolarisation in lung with the same genotype as TRR/l Ep-CKO, but no doxycycline (Dox) induction (g), was not affected compared with the normal control (h) at the age of 2 months (2M). i) Morphometric quantification of alveolar sizes by mean linear intercept (MLI) at different post-natal alveolarisation stages. About $85 \%$ of alveolarisation was accomplished in normal controls $(\square)$ at P14, while significant retardation of alveolar formation with $58 \%$ enlarged alveolar size occurred at P14 in TRR/l Ep-CKO mice ( $\square$ ) and remained at young adulthood. The conditional knockout was induced by Dox administration at embryonic day 6.5. \#: no Dox induction in mice with genotypes of $T \beta R / I^{f \times / f x}$ or T $\beta R / I^{\mathrm{fx} / \mathrm{fx}} / \mathrm{SPC}$-rtTA/TetO-Cre. ${ }^{*}: \mathrm{p}<0.05$. Scale bars $=250 \mu \mathrm{m}$.

with the majority of positively stained cells localised within the alveolar septa.

Therefore, lung epithelium-specific T $\beta R I I$ CKO mice were generated, by crossing $T \beta R I I^{f x f f x}$ mice with SPC-rtTA/TetO-Cre transgenic mice, in which Cre expression was induced in airway epithelial cells of the whole lung and distal bronchus by a lung epithelium-specific SPC promoter-driven $r t T A$ transgene, in combination with the inducing agent Dox given prior to lung formation (at E6.5) [21]. As a result of Cre-mediated loxP DNA recombination, floxed-TBRII exon 2 deletion in genomic DNA isolated from lung tissues was confirmed by PCR genotyping (fig. 2). Significant reduction of T $\beta$ RII protein in whole lung tissue lysates of T $\beta R I I$ Ep-CKO mice at P28 was also confirmed by Western blot (fig. 2).

\section{Abrogation of TRRII gene expression in lung epithelia from early mouse lung organogenesis resulted in retarded post- natal alveogenesis, but no detectable phenotype in prenatal lung development}

Newborn lung epithelium-specific TRRII Ep-CKO mice $\left(\mathrm{T} \beta R I^{\mathrm{fx} / \mathrm{fx}} / \mathrm{SPC}-\mathrm{rtTA} / \mathrm{TetO}-\mathrm{Cre}\right)$ breathed normally without any signs of respiratory distress. Histological study confirmed normal lung saccular structure formation in P1 T $\beta R I I$ Ep-CKO lung compared with littermate controls. However, markedly 
a)
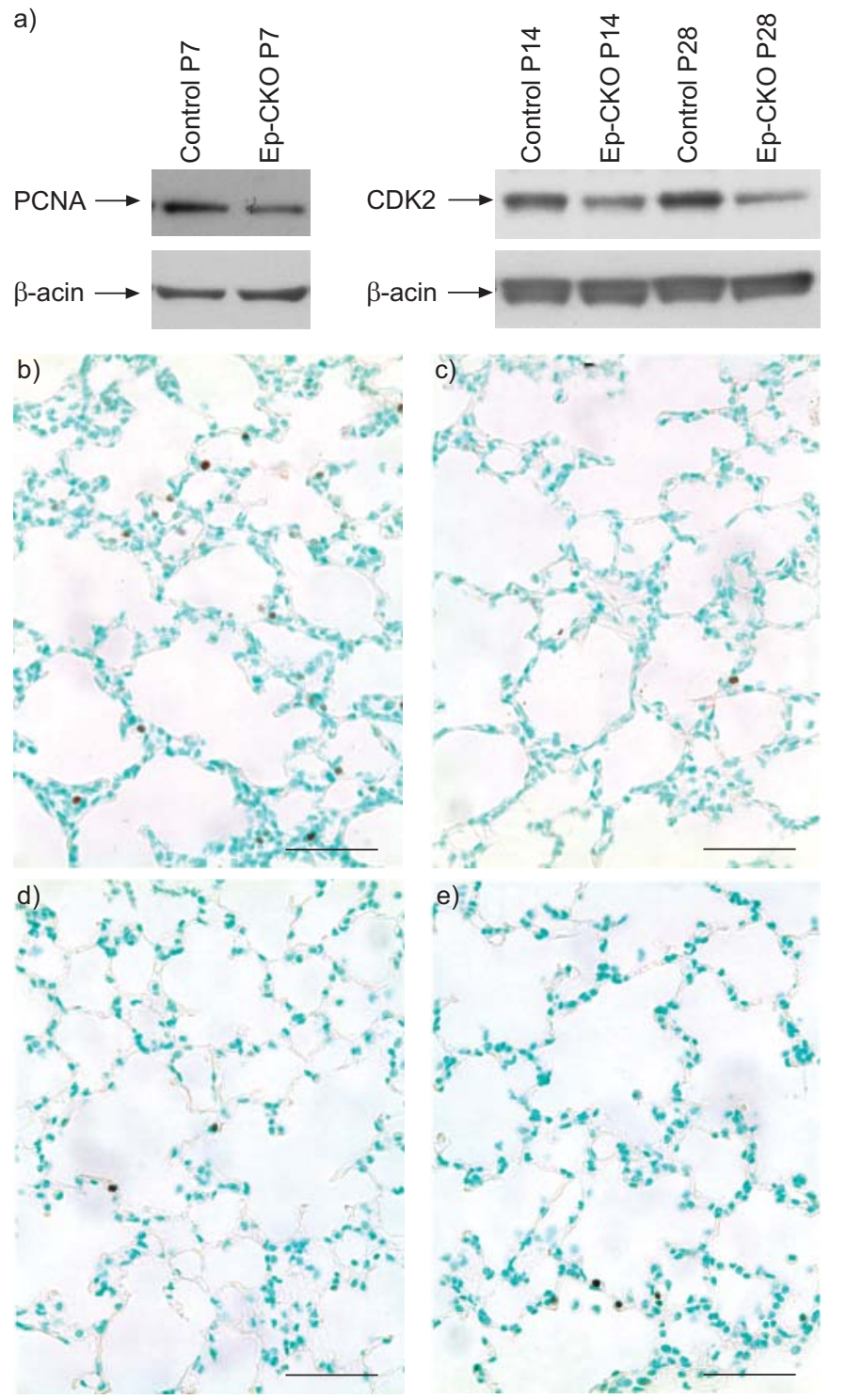

FIGURE 4. Abrogation of transforming growth factor- $\beta$ type II receptor (T $\beta$ RII) in lung epithelial cells resulted in decreased cell proliferation. a) Proliferating cell nuclear antigen (PCNA) and cyclin-dependent kinase (CDK)2 protein levels were reduced in lungs of lung epithelium-specific T $\beta$ RII conditional knockout (Ep-CKO) mice compared with controls, at post-natal day (P)7, P14 and P28. In these blots, $\beta$ actin was used as a loading control. Histological staining with PCNA (dark brown) at P7 in b) controls and c) T $\beta R / /$ Ep-CKO mice showed fewer PCNA-positive cells in the CKO mice. Apoptosis levels at P28 in d) controls and e) T $\beta R / l$ Ep-CKO mice were, however, similar, as shown by terminal deoxynucleotidyl transferasemediated deoxyuridine triphosphate nick-end labelling (dark brown). Scale bars $=50 \mu \mathrm{m}$.

retarded lung alveolarisation was detected in TBRII Ep-CKO mice during post-natal alveogenesis (fig. 3), which occurs from P5-P30 in mice. During mouse post-natal lung alveolarisation, secondary crests develop and extend to make new secondary septa that further subdivide terminal air sac structures, accompanied by decreased mean alveolar size. Therefore, the larger the alveolar size, the fewer the alveoli; thus, alveogenesis can be quantified by calculating MLI. At P7, during early alveolarisation, MLI in T $\beta R I I$ Ep-CKO lung was slightly higher than normal (fig. 3). As alveogenesis continued, the significant difference in MLI between T $\beta R I I$ Ep-CKO and normal control markedly increased at P14, and remained elevated to the end of alveolarisation (P28), as well as into early adulthood (age 2 months; fig. 3), suggesting a major maturational arrest of alveolarisation. In order to exclude the possibility that the reduced alveolarisation in TBRII Ep-CKO was caused by nonspecific effects of compound transgenic genotypes, lung alveolarisation was also compared between mice with the genotypes T $\beta R I I$ Ep-CKO and normal control, but without Dox induction. No change in alveolarisation, as examined by morphology and morphometric MLI measurement, was detected in the absence of Dox induction (fig. 3). In addition, mice with Dox-induced T $\beta R I I$ heterozygous genotype (TRRII $\mathrm{fx}^{\mathrm{f} /+} /$ SPC-rtTA/TetO-Cre) had normal lung alveolarisation, as seen in the controls. These data suggest that the retarded alveolarisation of T $\beta R I I$ Ep-CKO mice is specifically due to lack of T $\beta R I I$ function in lung epithelia.

\section{Conditional knockout of T/RII function in lung epithelial cells resulted in abnormal cell proliferation and differentiation during post-natal lung alveogenesis}

Secondary septal formation during alveogenesis is a complicated process requiring fine coordination of outgrowth of epithelial cells, extension and simplification of capillary networks, alveolar myofibroblast involvement and correct deposition of the elastic interstitial matrix. This is regulated by many factors including TGF- $\beta$ signalling. Abrogation of T $\beta$ RII in lung epithelial cells resulted in decreased cell proliferation during the alveolarisation stage, as indicated by reduced PCNA protein level and fewer PCNA-positive cells in TRRII Ep-CKO mouse lungs at P7 (fig. 4a-c). Furthermore, decreased cell proliferation was also verified by reduced CDK2 expression in P14 and P28 TRRII Ep-CKO lungs (fig. 4a). However, apoptosis during lung alveolarisation, particularly at the later alveolarisation stage of P28, was not increased, as shown by TUNEL staining (fig. $4 \mathrm{~d}$ and e). Therefore, reduced cell proliferation in affected cell lineages, rather than increased cell death, may cause fewer alveolar septa to form in the TRRII Ep-CKO lung.

Cell differentiation was also evaluated by immunostaining the molecular markers of different cell lineages in the lung at P14, a time at which obvious retardation of alveolarisation was seen in the TRRII Ep-CKO lung. SPC and AQP5 are cell-specific markers for alveolar epithelial cells (AEC) type II and type I, respectively. No significant change in SPC-positive cells was observed in TRRII Ep-CKO lungs (fig. 5a and b). However, AQP5-positive cells and the intensity of AQP5 in positively stained cells were markedly reduced when T $\beta R I I$ was abrogated in lung epithelium (fig. $5 \mathrm{c}$ and d), suggesting that reduced AECI lineage differentiation and/or amplification may be an important cellular mechanism underlying retarded alveogenesis in the TBRII Ep-CKO mouse lung. In addition, myofibroblasts and related important extracellular proteins were evaluated by detecting SMA, laminin and elastin fibre deposition in septal structures (fig. 5e-1). Laminin, a major protein component in the capillary basement membrane, was similarly distributed in the septal tips of both TRRII Ep-CKO and the control mouse lungs, suggesting normal capillary 


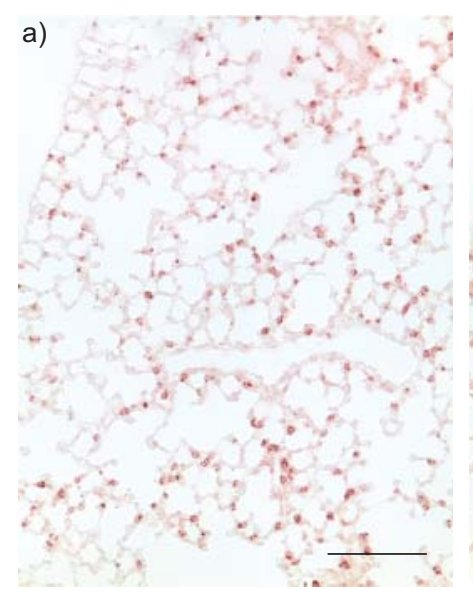

e)
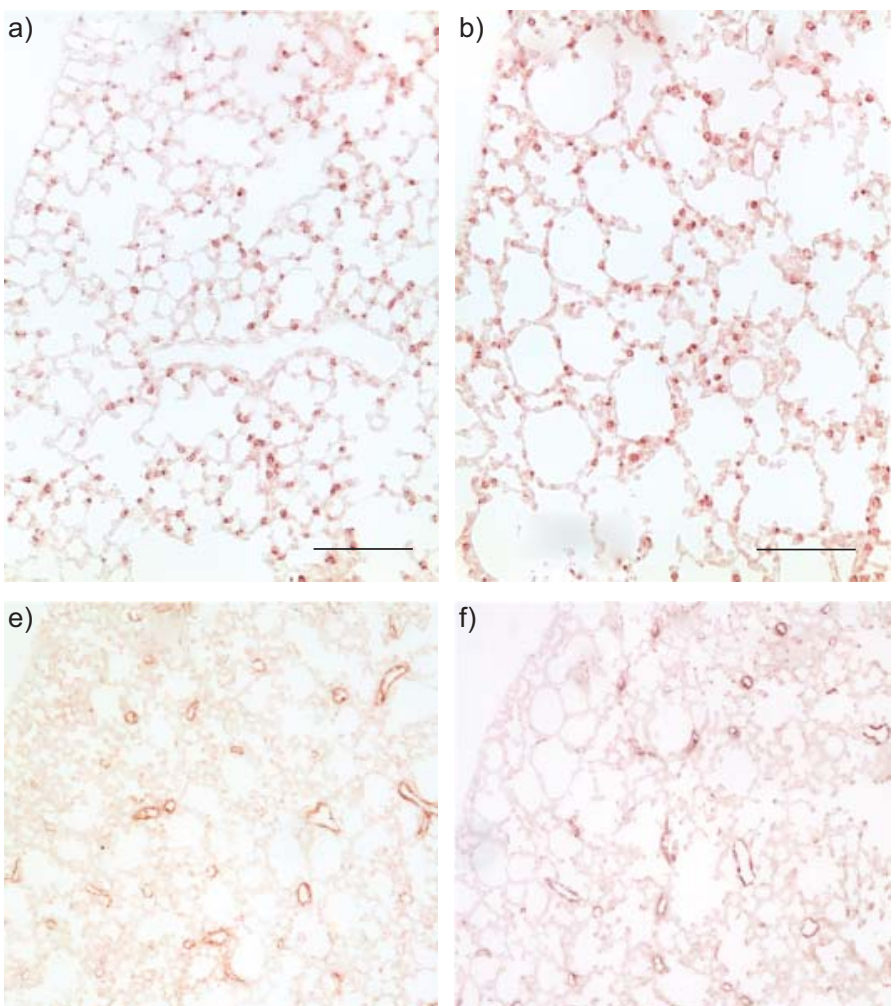

f)
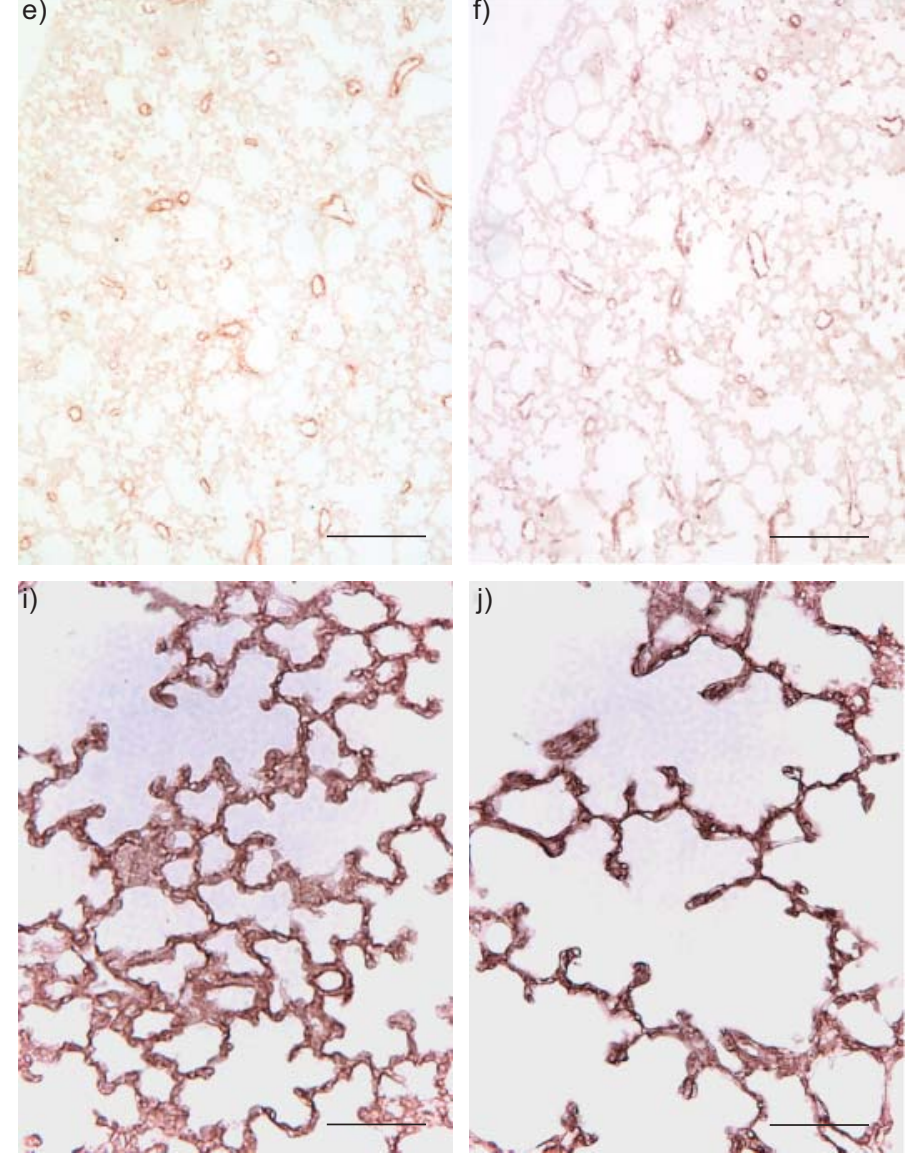
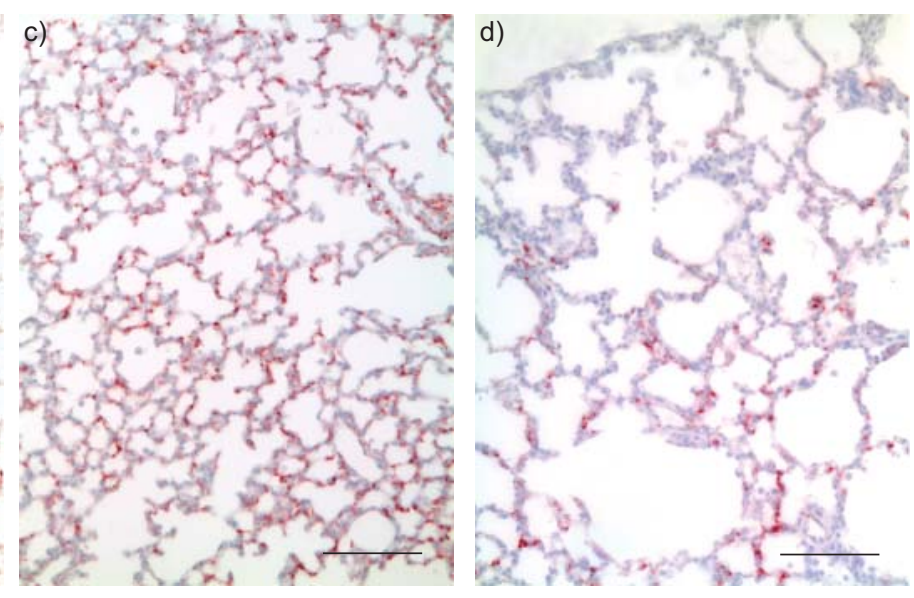

g)

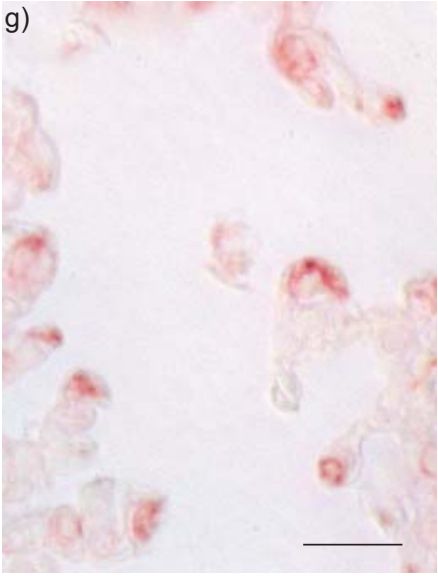

h)
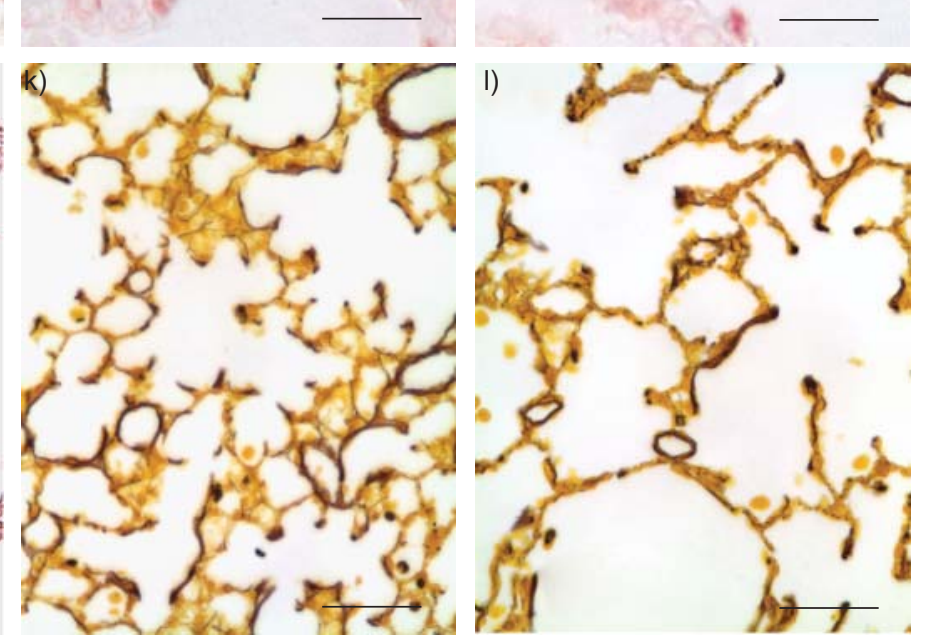

FIGURE 5. Cell differentiation was evaluated in control littermates (a, c, e, g, i and k) and lung epithelium-specific transforming growth factor- $\beta$ type II receptor (T $\beta R \| l)$ conditional knockout (Ep-CKO) mice (b, d, f, h, j and I) at post-natal day 14. Immunostaining for surfactant protein-C (a and b) showed no significant change, but aquaporin 5

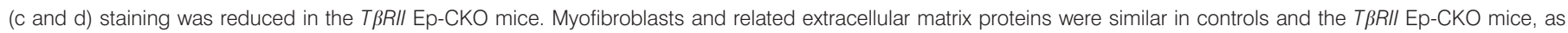
demonstrated by immunostaining for $\alpha$-smooth muscle actin (e-h), laminin (i and j) and elastin ( $k$ and l). a-d) Scale bars $=100 \mu \mathrm{m}$. e and f) Scale bars $=200 \mu \mathrm{m}$. $g$ and $h$ ) Scale bars $=20 \mu \mathrm{m}$. i-l) Scale bars $=50 \mu \mathrm{m}$.

outgrowth. A similar pattern of SMA positive signal was detected in smooth muscle cells surrounding bronchioles and large blood vessels, as well as in myofibroblasts within septal structures of both T $\beta R I I$ Ep-CKO and normal control lungs. Furthermore, deposition of elastin fibres at the tips of alveolar septal structures of T $\beta R I I$ Ep-CKO lungs remained similar to normal controls, suggesting that alterations in mesenchymal cell proliferation or differentiation or extracellular matrix deposition were not the direct cause of abnormal alveolarisation in the TRRII Ep-CKO mice.

\section{Conditional abrogation of TRRII in mouse lung mesenchymal cells during foetal lung development}

Since T $\beta$ RII was also found to be expressed in the mesenchyme of mouse embryonic and adult lungs (fig. 1), T $\beta$ RII-mediated TGF- $\beta$ signalling in mesenchymal cells may play a unique role 

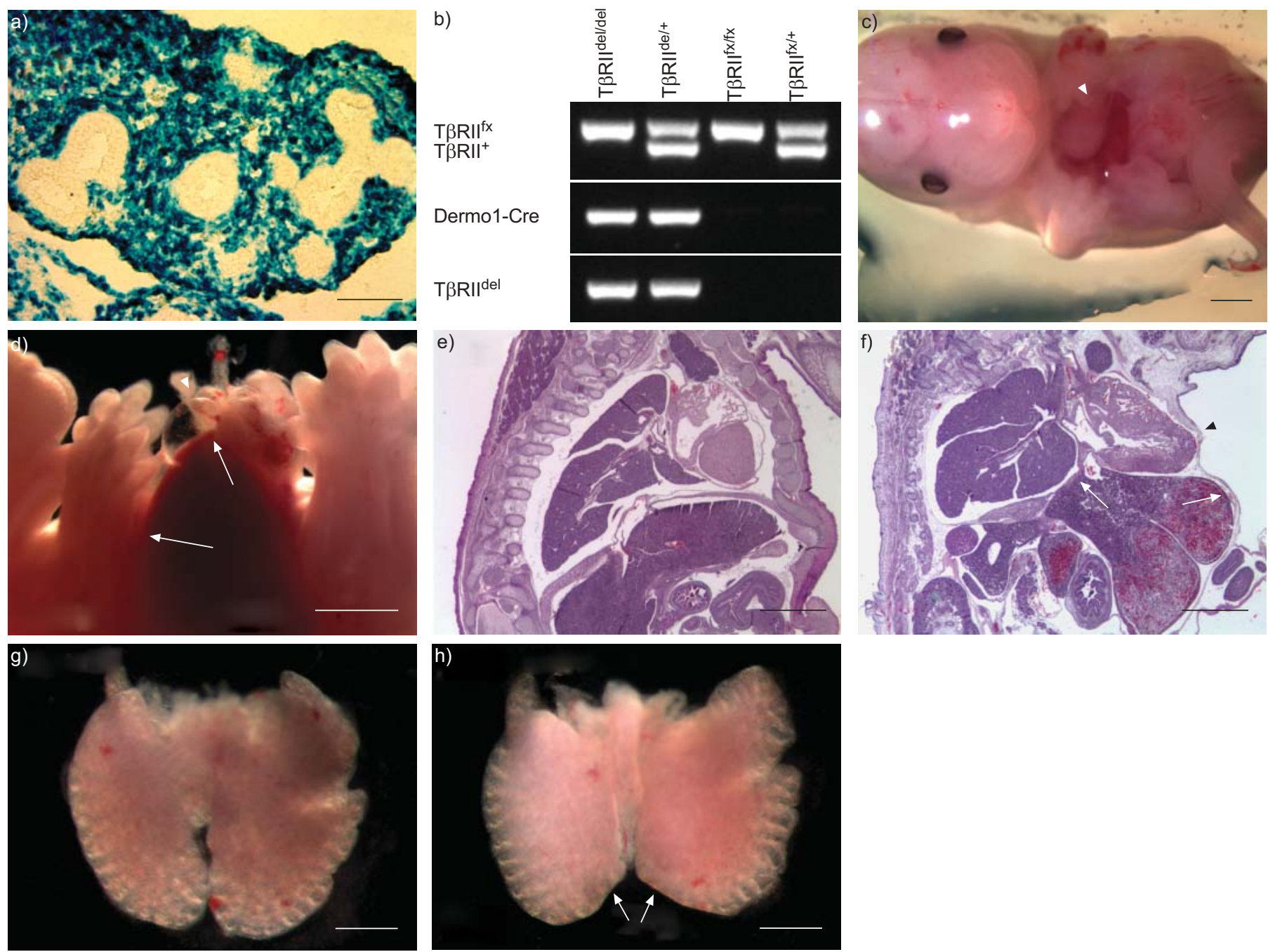

FIGURE 6. Mesoderm-specific transforming growth factor- $\beta$ type II receptor (TRRII) conditional knockout (Me-CKO) mice. a) Lung mesenchymal-specific expression of Cre in Dermo1-Cre mice was verified by crossing Dermo1-Cre and Rosa26R mice in which only cells with Cre-mediated loxP DNA recombination expressed LacZ. Tissue section from LacZ-stained (blue) embryonic day (E)12.5 lung. The whole lung, with the exception of airway epithelial cells, was positively stained for LacZ. b) PCR genotypes of lung tissue genomic DNA. Gross top (c) and side (d) views of a TRRII Me-CKO foetus at E14.5. Defective ventral body wall formation, as shown by a membrane instead of skin, muscle and ribs (arrowheads), was apparent in the chest and upper abdomen. In addition, protrusion of the liver into the chest through a diaphragmatic hernia was also observed (d; arrows). Haematoxylin and eosin-stained sagittal sections of E16 control (e) and TRR/l Me-CKO (f) foetuses. f) Defective body wall (arrowhead) and protrusion of the liver (arrows) is shown. Gross views of E14.5 lung of control (g) and TRR/l Me-CKO (h) mice. h) Deformity of the lung, particularly both left and right inferior lobes (arrows),

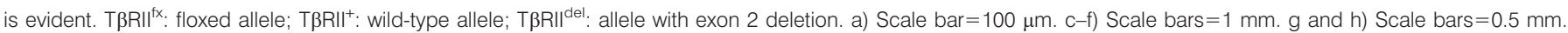

in regulating embryonic lung formation, particularly branching morphogenesis. By taking advantage of mesoderm-derived tissue-specific expression of Cre in the Dermo1-Cre knock-in driver mouse line [22], mesenchyme-specific Cre-mediated loxP DNA recombination was achieved in multiple mouse embryonic organs, including the lung (fig. 6a). T $\beta R I f^{f x / f x}$ mice were then crossed with Dermo1-Cre mice to generate T $\beta R I I \mathrm{Me}-$ $\mathrm{CKO}$ mice, as shown by their genotypes (fig. 6b). These T $\beta R I I$ $\mathrm{Me}-\mathrm{CKO}$ mice had severe defects in other important developmental processes, including defective secondary ventral body wall formation, congenital diaphragmatic hernia and abnormal cardiac development (fig. 6c-f). These nonpulmonary abnormalities were all due to disrupted TGF- $\beta$ signalling in other key mesoderm-derived tissues. Lung bud formation in TRRII
Me-CKO mice was not noticeably affected at the early stage (E12.5), but obvious deformity of the lung, particularly in the left and right inferior lobes, was observed at $\sim$ E14.5 (fig. $6 \mathrm{~g}$ and $h$ ), which could be attributed to abnormal positioning of the heart and liver due to defective thoracic wall formation and diaphragmatic closure. This Dermo1-Cre-driven T $\beta R I I$ conditional knockout was lethal at $\sim$ E16.5, possibly due to severe defects in other organs, including the heart.

\section{Mesenchymal abrogation of T/RII signalling in prenatal lungs disrupted normal branching morphogenesis}

By gross comparison of T $\beta R I I \mathrm{Me}-\mathrm{CKO}$ and control mouse lungs at the early stage of branching morphogenesis (E12.5), no significant changes in early lung branching were found (fig. 7a 

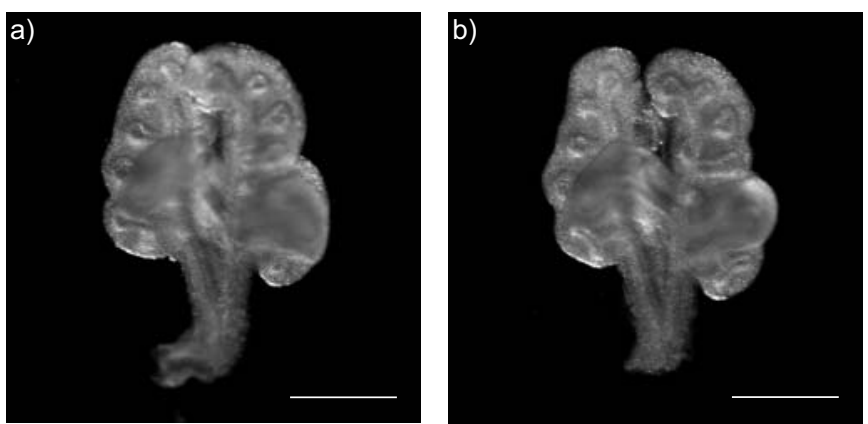

c)

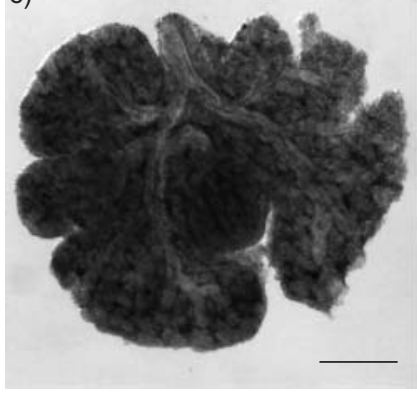

d)
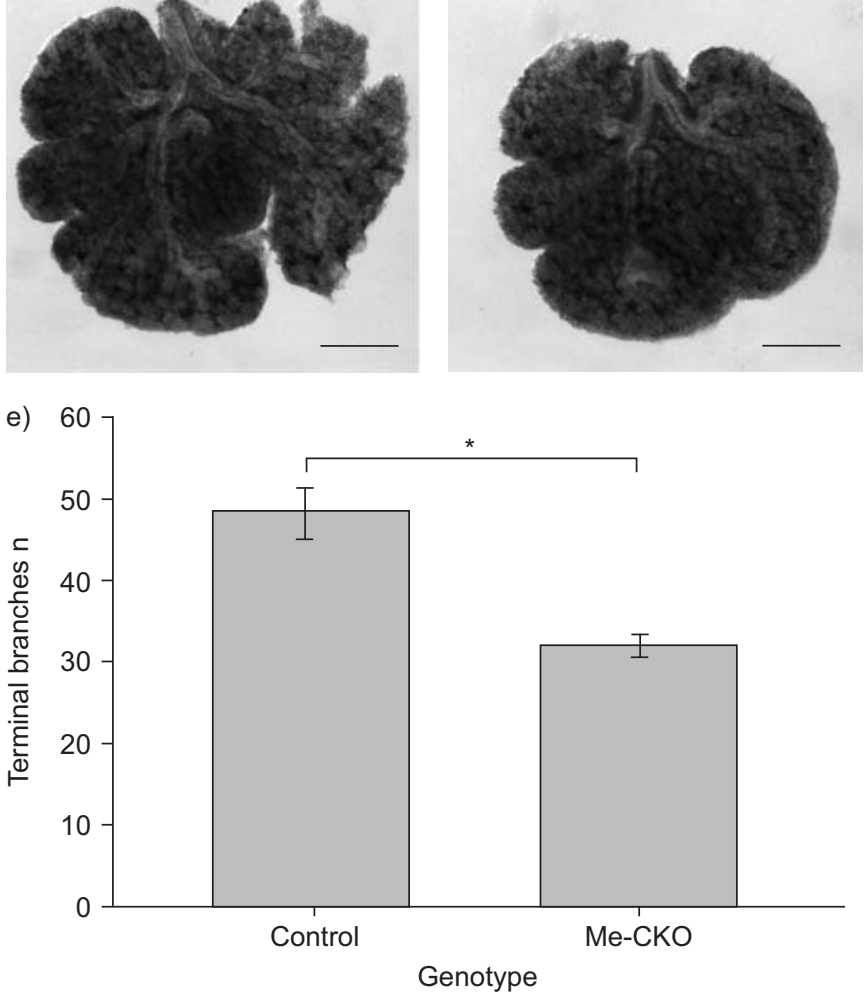

FIGURE 7. Lung branching defect in mesoderm-specific transforming growth factor- $\beta$ type II receptor (TRRII) conditional knockout (Me-CKO) mouse lung in lung explant culture. Controls (a) were compared with grossly normal embryonic day (E)12.5 lungs isolated from T $\beta R / l$ Me-CKO mice (b). However, compared with controls (c), reduced lung branching in TRR/l Me-CKO lung (d) was detected after 3 days of culture in vitro. e) The numbers of peripheral airway branches were quantified at the end of organ culture. Significant reduction of peripheral branches in TRRIl Me-CKO lung explants was observed, compared with normal control. *: $p<0.05$. Scale bars $=0.5 \mathrm{~mm}$.

and b). However, histological study found slight dilation of peripheral airways accompanied by reduced mesenchymal cell density in TRRII Me-CKO lung at E14.5 (fig. 8a and b). These phenotypic changes were more evident 2 days later at E16.5. As shown by PCNA immunostaining, the number of proliferating cells in TRRII Me-CKO lungs was decreased in both the airway epithelium and surrounding mesenchyme compared with normal littermate controls (fig. 8e and f). However, differentiation of peripheral airway epithelial cells and mesenchymal myofibroblasts / smooth muscle cells was not changed, as shown by SPC and SMA immunostaining (fig. $8 \mathrm{~g}-\mathrm{j}$ ).
In order to exclude the possibility that abnormal lung branching in TRRII Me-CKO was due to physical distortion of the developing lung, whole embryonic lung explant culture was performed. Embryonic lung explants were isolated at E12.5, when no branching difference was observed between TRRII Me-CKO and normal controls (fig. 7a and b). After 3 days of culture, the numbers of terminal branches in the growing lung explants were counted and compared between T $\beta R I I$ Me-CKO and controls (fig. 7c-e). Significantly reduced numbers of terminal branches were detected in T $\beta R I I$ Me-CKO lung explants, $66 \%$ of the number counted in normal controls ( $32 \pm 2$ versus $48 \pm 3$, respectively; $\mathrm{p}<0.05)$. In contrast, lung branching in 3-day cultures of T $\beta R I I$ Ep-CKO lung explants was not significantly changed compared with normal control (data not shown), suggesting that T $\beta$ RII-mediated signalling in embryonic and foetal lung mesenchyme plays an essential role during lung branching morphogenesis, while T $\beta$ RII-mediated signalling in airway epithelial cells may not be essential to early embryonic lung branching, but is critical for post-natal alveolarisation.

\section{DISCUSSION}

Lung development includes both early airway branching morphogenesis and late peripheral alveolarisation. Disruption of either process will result in abnormal lung structure and function, with the consequence of either respiratory failure, if early lung formation is severely affected, or susceptibility to lung diseases during later life, if mild changes occur in the developing lung [5]. Epithelial-mesenchymal interaction plays an important role in regulating normal lung formation, possibly through direct cell-cell contact, as well as indirectly through changing growth factor secretion and extracellular matrix protein deposition. TGF- $\beta$ s are one group of important growth factors involved in regulating lung development.

TGF- $\beta 1,-\beta 2$ and $-\beta 3$ have all been detected in murine embryonic lungs [29-32]. Null mutations of TGF- $\beta$ s result in either abnormal foetal lung development and/or excessive post-natal lung inflammation, indicating that TGF- $\beta$ signalling is essential for normal lung formation and function [11-14]. In contrast, overexpression of TGF- $\beta 1$, driven by a $3.7 \mathrm{~kb}$ human SPC promoter in lung epithelium of transgenic mice, caused a hypoplastic lung phenotype [16], suggesting that appropriate levels of TGF- $\beta$ signalling at the right place and right time are essential for normal lung organogenesis. However, whole organ alteration of TGF- $\beta$ ligand level may affect TGF- $\beta$ signalling activities in both lung epithelial and mesenchymal cells by changing autocrine and/or paracrine signalling pathways, which are difficult to distinguish. Therefore, in order to study the regulatory functions of endogenous TGF- $\beta$ signalling in lung epithelial versus mesenchymal cells during lung development, the current authors selectively abrogated TGF- $\beta$ intracellular signalling activity using Cre/loxP approaches, by deleting T $\beta$ RII functional protein production specifically in either lung epithelium or mesenchyme with SPC-rtTA/TetO-Cre and Dermo1-Cre driver lines, respectively.

Interestingly, blockade of endogenous T $\beta R I I$ function in airway epithelial cells alone (Ep-CKO) failed to elicit any detectable alterations to prenatal mouse lung formation, particularly branching morphogenesis in vivo. The neonatal $T \beta R I I$ Ep-CKO mice breathed normally and displayed similar 

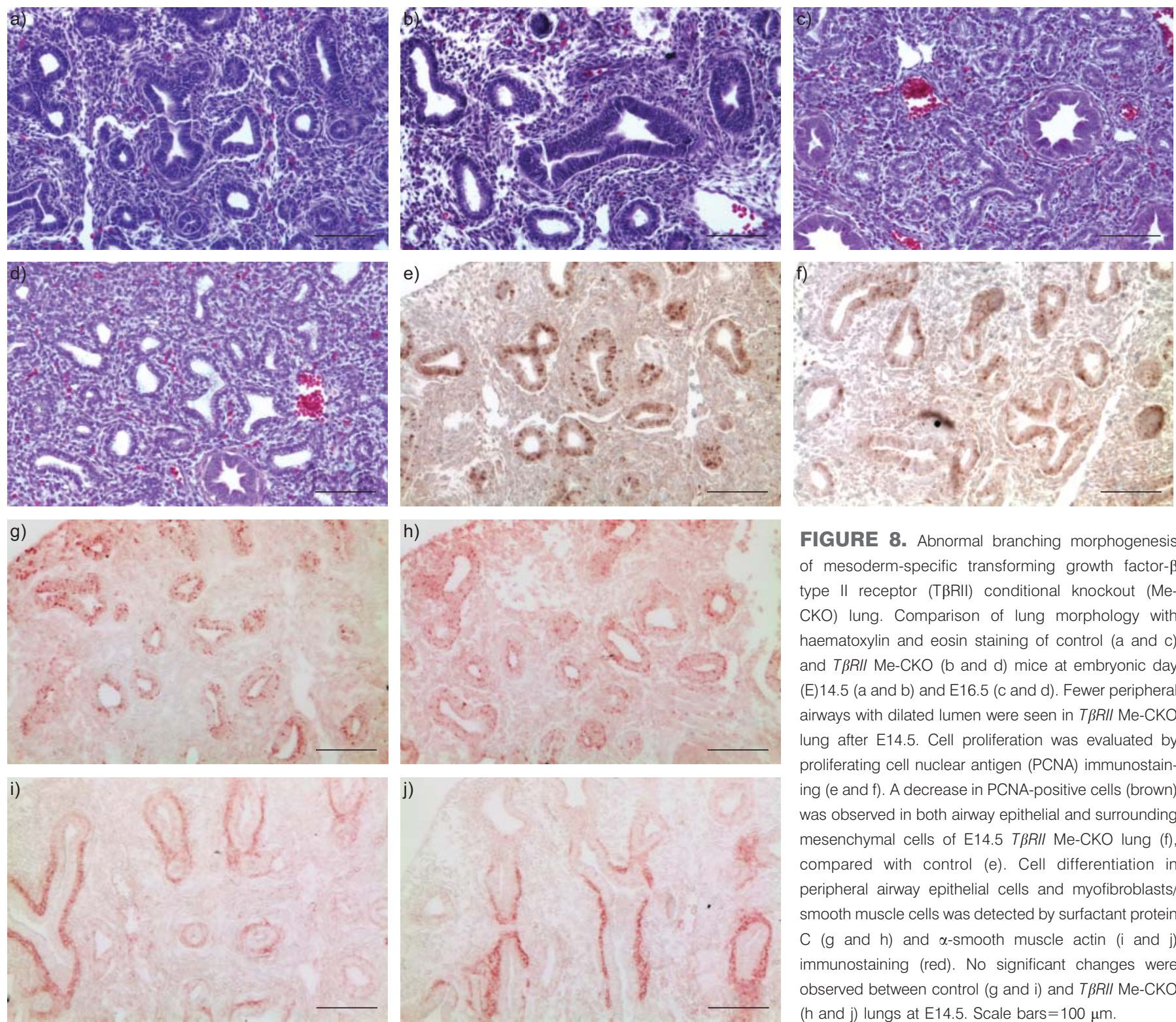

FIGURE 8. Abnormal branching morphogenesis of mesoderm-specific transforming growth factor- $\beta$ type II receptor (TRRII) conditional knockout (Me$\mathrm{CKO})$ lung. Comparison of lung morphology with haematoxylin and eosin staining of control (a and $\mathrm{c}$ ) and TRRII Me-CKO (b and d) mice at embryonic day (E)14.5 ( $\mathrm{a}$ and b) and E16.5 (c and d). Fewer peripheral airways with dilated lumen were seen in T $\beta R / l$ Me-CKO lung after E14.5. Cell proliferation was evaluated by proliferating cell nuclear antigen (PCNA) immunostaining (e and f). A decrease in PCNA-positive cells (brown) was observed in both airway epithelial and surrounding mesenchymal cells of E14.5 TRRIl Me-CKO lung ( $\mathrm{f}$ ), compared with control (e). Cell differentiation in peripheral airway epithelial cells and myofibroblasts/ smooth muscle cells was detected by surfactant protein C ( $g$ and $h$ ) and $\alpha$-smooth muscle actin ( $i$ and $j$ ) immunostaining (red). No significant changes were observed between control ( $\mathrm{g}$ and i) and T $\beta R / / \mathrm{Me}-\mathrm{CKO}$ ( $h$ and j) lungs at E14.5. Scale bars $=100 \mu \mathrm{m}$.

saccular organisation to that seen in control mice at P1. However, secondary alveolar septa formation was severely retarded in T $\beta R I I$ Ep-CKO mice during post-natal mouse lung alveogenesis. Alveolarisation is a complicated process, with coordinated growth of alveolar epithelial cells (both AECI and AECII), capillary endothelial cells and myofibroblasts and deposition of extracellular matrix, particularly elastin. Cell proliferation and differentiation in each of these cell lineages contribute to the secondary septa and, thus, to the related alveolar surface formation, generating sufficient gas exchange membrane between terminal airspaces and the pulmonary circulation. By measuring the cell cycle-specific protein markers PCNA and CDK2, it was found that overall cell proliferation in the T $\beta R I I$ Ep-CKO lung was reduced, suggesting that T $\beta$ RII-mediated TGF- $\beta$ signalling in lung epithelial cells is essential for directly regulating epithelial cell growth and/or indirectly affecting endothelial cells or myofibroblasts. To further narrow the affected cell lineages in T $\beta R I I$ Ep-CKO lungs, expression patterns of cell-specific markers were examined in the different types of cells. No significant changes in myofibroblasts, as stained by SMA, were observed in septal structures of TRRII Ep-CKO mouse lungs. Consistently, deposition of elastin fibres in the septal extracellular spaces was not changed in TRRII Ep-CKO lungs. These data suggest that alveogenesis, controlled by the platelet-derived growth factor pathway, which promotes myofibroblast growth, is not indirectly affected by abrogating epithelial TGF- $\beta$ signalling activity in this mouse model [33]. Similarly, normal deposition of laminin, a major basement membrane component of the capillary network, was detected at the tips of septal structures, indicating normal capillary endothelial development in T $\beta R I I$ Ep$\mathrm{CKO}$ mice. Moreover, a comparable distribution of SPC positively stained epithelial cells was observed in control and T $\beta R I I$ Ep-CKO lungs, suggesting that lack of TGF- $\beta$ signalling activity in lung epithelial cells does not disrupt normal SPCpositive AECII and/or related progenitor cell differentiation. 
However, AQP5 positively stained AECI cells were markedly reduced in TBRII Ep-CKO lungs, indicating that, in lung epithelial cells, T $\beta$ RII-mediated TGF- $\beta$ signalling alone may directly regulate AECI differentiation and expansion in vivo. Reduced AECI cell populations may, thus, contribute to reduced secondary septal growth and alveolar surface membrane formation. Consistent with the present in vivo result, BHASKARAN et al. [34] recently reported that, in primary cultured rat lung epithelial cells, abrogation of endogenous TGF- $\beta$ signalling by adding TGF$\beta 1$ neutralisation antibody or silencing downstream Smad4 function using RNA interference inhibited AECI cell differentiation. In addition, it has previously been shown that mice with conventional knockout of T $\beta$ RII downstream Smad3 also suffered from retarded lung alveogenesis [23]. Together, these data strongly suggest that TGF- $\beta$-Smad3-dependent signalling activity in lung epithelial cells plays a critical regulatory role in promoting AECI cell differentiation and lineage expansion, particularly during lung alveogenesis.

Interestingly, in conventional Smad3 knockout mice, subsequent destruction of preformed alveolar structures follows after abnormal alveolarisation around P28, resulting in central lobular emphysema-like pathology [23]. A conventional null mutation of latent TGF- $\beta$ binding protein-4, which is required for mature TGF- $\beta$ peptide secretion and activation, also results in abnormal lung alveolarisation in neonates and development of emphysema in adult mice [35]. However, no emphysema-like lung tissue destruction was observed in the present lung epithelial-specific TRRII conditional knockout, although retarded alveolarisation persisted into adulthood. These data suggest that TGF- $\beta$-Smad signalling activity in lung epithelial cells per se is essential for mature lung development, and that disruption of TGF- $\beta$-Smad signalling in other lung cells, including myofibroblasts and/or inflammatory cells (macrophages and neutrophils), is required for proteinase-mediated tissue destruction [23]. Further dissection of related mechanisms in vivo will require a TRRII CKO in other cell lineages, such as leukocytes, macrophages and/or myofibroblasts, in combination with a T $\beta R I I$ mutation in lung epithelial cells.

Previous studies using transgenic and ex vivo organ culture approaches indicate that TGF- $\beta$ signalling plays an important regulatory role in embryonic lung branching morphogenesis $[15,16]$. Surprisingly, lung branching morphogenesis was normal when endogenous T $\beta$ RII function in mouse embryonic lung airway epithelial cells was blocked in vivo. In contrast, abrogation of T $\beta$ RII function in mesoderm-derived lung mesenchymal cells resulted in a relatively mild reduction of lung branching morphogenesis, detected only at E14.5 and later, but not in early gestation (E12.5). This is consistent with the immunostaining data, which showed that T $\beta$ RII expression in embryonic lung mesenchyme was only detected from midgestation onwards. In contrast to SPC-rtTA/TetO-Cre-driven Cre expression specifically in lung epithelia, Dermo1-Cre expression is not restricted to lung mesenchymal tissue. Therefore, abrogation of T $\beta$ RII function using a Dermo1-Cre driver mouse line generated T $\beta R I I \mathrm{CKO}$ in multiple organs, including the ventral body wall, heart and diaphragm. Thus, multiple defects in T $\beta R I I$ Me-CKO mice made it difficult to determine the related and specific mechanisms underlying the lung phenotype. In particular, the diaphragmatic hernia-like defect may also contribute directly to abnormal lung branching morphogenesis at embryonic stages [36, 37]. For example, lung hypoplasia was also found at early embryonic stages of mice lacking the Friend of GATA-1 (Fog)2-GATA binding protein (Gata) 4 interaction, prior to development of congenital diaphragmatic hernia caused by loss-of-function mutations in Fog2 or Gata4 [38, 39]. This suggests that pulmonary hypoplasia could be an independent developmental defect, instead of a secondary consequence of increased intrathoracic pressure due to a dislocation of abdominal organs to the chest via the diaphragmatic hernia. In addition, marked physical deformity of the lungs, caused by diaphragmatic hernia and thoracic ventral body wall defects, may also indirectly and adversely affect normal lung growth after E12.5 [38, 39]. Nevertheless, by ex vivo culture, the present study verified that endogenous T $\beta$ RII function in lung mesenchyme alone is essential for normal lung branching. However, the TRRII Me-CKO mouse line generated by crossing floxed TRRII and Dermo1-Cre mice may not be an ideal model for further dissection of the mechanisms by which TGF- $\beta$ signalling in mesenchyme regulates airway epithelial branching, due to these multiple confounding factors.

In conclusion, transforming growth factor- $\beta$ signalling mediated by transforming growth factor- $\beta$ type II receptor plays distinct roles in developing mouse lung epithelium versus mesenchyme. The integrated functions of transforming growth factor- $\beta$ type II receptor are very important in embryonic lung branching morphogenesis and post-natal lung alveolarisation. The developmental immaturity of lung structure and function, resulting from loss-of-function mutations in transforming growth factor- $\beta$ signalling pathway components, may, therefore, contribute to early post-natal respiratory problems, such as bronchopulmonary dysplasia. It may also increase the susceptibility to respiratory diseases later in life, including emphysema.

\section{ACKNOWLEDGEMENTS}

The authors would like to thank D.M. Ornitz (Washington University, St Louis, MO, USA) for providing the Dermo1-Cre mice and J.A. Whitsett (Cincinnati Children's Hospital Medical Center, Cincinnati, OH, USA) for providing the SPC-rtTA/ TetO-Cre mice. They also thank X. Xu (Center for Craniofacial Molecular Biology, University of Southern California, Los Angeles, CA, USA) for initial discussions about TRRII conditional knockouts, and P. Minoo (Keck School of Medicine, University of Southern California) for critical reading of the manuscript.

\section{REFERENCES}

1 Ten Have-Opbroek AA. Lung development in the mouse embryo. Exp Lung Res 1991; 17: 111-130.

2 Hilfer SR. Morphogenesis of the lung: control of embryonic and fetal branching. Annu Rev Physiol 1996; 58: 93-113.

3 Hogan BL. Morphogenesis. Cell 1999; 96: 225-233.

4 Hogan BL, Grindley J, Bellusci S, Dunn NR, Emoto H, Itoh N. Branching morphogenesis of the lung: new models for a classical problem. Cold Spring Harb Symp Quant Biol 1997; 62: 249-256. 
5 Warburton D, Gauldie J, Bellusci S, Shi W. Lung development and susceptibility to chronic obstructive pulmonary disease. Proc Am Thorac Soc 2006; 3: 668-672.

6 Warburton D, Schwarz M, Tefft D, Flores-Delgado G, Anderson KD, Cardoso WV. The molecular basis of lung morphogenesis. Mech Dev 2000; 92: 55-81.

7 Shi Y, Massagué J. Mechanisms of TGF- $\beta$ signaling from cell membrane to the nucleus. Cell 2003; 113: 685-700.

8 Massagué J. TGF- $\beta$ signal transduction. Annu Rev Biochem 1998; 67: 753-791.

9 Attisano L, Wrana JL. Smads as transcriptional comodulators. Curr Opin Cell Biol 2000; 12: 235-243.

10 Derynck R, Zhang YE. Smad-dependent and Smadindependent pathways in TGF- $\beta$ family signalling. Nature 2003; 425: 577-584.

11 Kaartinen V, Voncken JW, Shuler C, et al. Abnormal lung development and cleft palate in mice lacking TGF- $\beta 3$ indicates defects of epithelial-mesenchymal interaction. Nat Genet 1995; 11: 415-421.

12 Shi W, Heisterkamp N, Groffen J, Zhao J, Warburton D, Kaartinen V. TGF- 33 -null mutation does not abrogate fetal lung maturation in vivo by glucocorticoids. Am J Physiol 1999; 277: L1205-L1213.

13 Sanford LP, Ormsby I, Gittenberger-de Groot AC, et al. TGF- $\beta 2$ knockout mice have multiple developmental defects that are non-overlapping with other TGF- $\beta$ knockout phenotypes. Development 1997; 124: 2659-2670.

14 Kulkarni AB, Huh CG, Becker D, et al. Transforming growth factor $\beta 1$ null mutation in mice causes excessive inflammatory response and early death. Proc Natl Acad Sci USA 1993; 90: 770-774.

15 Zhao J, Shi W, Chen H, Warburton D. Smad7 and Smad6 differentially modulate transforming growth factor $\beta$ induced inhibition of embryonic lung morphogenesis. J Biol Chem 2000; 275: 23992-23997.

16 Zhou L, Dey CR, Wert SE, Whitsett JA. Arrested lung morphogenesis in transgenic mice bearing an SP-C-TGF- $\beta 1$ chimeric gene. Dev Biol 1996; 175: 227-238.

17 Dammann CE, Ramadurai SM, McCants DD, Pham LD, Nielsen HC. Androgen regulation of signaling pathways in late fetal mouse lung development. Endocrinology 2000; 141: 2923-2929.

18 Torday JS, Kourembanas S. Fetal rat lung fibroblasts produce a TGF- $\beta$ homolog that blocks alveolar type II cell maturation. Dev Biol 1990; 139: 35-41.

19 Oshima M, Oshima $H$, Taketo MM. TGF- $\beta$ receptor type II deficiency results in defects of yolk sac hematopoiesis and vasculogenesis. Dev Biol 1996; 179: 297-302.

20 Chytil A, Magnuson MA, Wright CV, Moses HL. Conditional inactivation of the TGF- $\beta$ type II receptor using Cre:Lox. Genesis 2002; 32: 73-75.

21 Perl AK, Wert SE, Nagy A, Lobe CG, Whitsett JA. Early restriction of peripheral and proximal cell lineages during formation of the lung. Proc Natl Acad Sci USA 2002; 99: 10482-10487.

$22 \mathrm{Yu} \mathrm{K}, \mathrm{Xu} \mathrm{J}$, Liu Z, et al. Conditional inactivation of FGF receptor 2 reveals an essential role for FGF signaling in the regulation of osteoblast function and bone growth. Development 2003; 130: 3063-3074.
23 Chen H, Sun J, Buckley S, et al. Abnormal mouse lung alveolarization caused by Smad3 deficiency is a developmental antecedent of centrilobular emphysema. Am J Physiol Lung Cell Mol Physiol 2005; 288: L683-L691.

24 Thurlbeck WM. Measurement of pulmonary emphysema. Am Rev Respir Dis 1967; 95: 752-764.

25 Dunnill MS. Quantitative methods in the study of pulmonary pathology. Thorax 1962; 17: 320-328.

26 Torday JS, Nielsen HC, Fencl Mde M, Avery ME. Sex differences in fetal lung maturation. Am Rev Respir Dis 1981; 123: 205-208.

27 Shi W, Chen H, Sun J, et al. TACE is required for fetal murine cardiac development and modeling. Dev Biol 2003; 261: 371-380.

28 Sun J, Zhuang FF, Mullersman JE, et al. BMP4 activation and secretion are negatively regulated by an intracellular gremlin-BMP4 interaction. J Biol Chem 2006; 281: 2934929356.

29 Pelton RW, Johnson MD, Perkett EA, Gold LI, Moses HL. Expression of transforming growth factor- $\beta 1,-\beta 2$, and $-\beta 3$ mRNA and protein in the murine lung. Am J Respir Cell Mol Biol 1991; 5: 522-530.

30 Pelton RW, Saxena B, Jones M, Moses HL, Gold LI. Immunohistochemical localization of TGF- $\beta 1$, TGF- $\beta 2$, and TGF- $\beta 3$ in the mouse embryo: expression patterns suggest multiple roles during embryonic development. J Cell Biol 1991; 115: 1091-1105.

31 Millan FA, Denhez F, Kondaiah P, Akhurst RJ. Embryonic gene expression patterns of TGF- $\beta 1,-\beta 2$ and $-\beta 3$ suggest different developmental functions in vivo. Development 1991; 111: 131-143.

32 Schmid P, Cox D, Bilbe G, Maier R, McMaster GK. Differential expression of TGF- $\beta 1,-\beta 2$ and $-\beta 3$ genes during mouse embryogenesis. Development 1991; 111: 117-130.

33 Boström H, Willetts K, Pekny M, et al. PDGF-A signaling is a critical event in lung alveolar myofibroblast development and alveogenesis. Cell 1996; 85: 863-873.

34 Bhaskaran M, Kolliputi N, Wang Y, Gou D, Chintagari NR, Liu L. Trans-differentiation of alveolar epithelial type II cells to type I cells involves autocrine signaling by transforming growth factor $\beta 1$ through the Smad pathway. I Biol Chem 2007; 282: 3968-3976.

35 Sterner-Kock A, Thorey IS, Koli K, et al. Disruption of the gene encoding the latent transforming growth factor- $\beta$ binding protein 4 (LTBP-4) causes abnormal lung development, cardiomyopathy, and colorectal cancer. Genes Dev 2002; 16: 2264-2273.

36 Kinane TB. Lung development and implications for hypoplasia found in congenital diaphragmatic hernia. Am J Med Genet C Semin Med Genet 2007; 145: 117-124.

37 Rottier R, Tibboel D. Fetal lung and diaphragm development in congenital diaphragmatic hernia. Semin Perinatol 2005; 29: 86-93.

38 Ackerman KG, Wang J, Luo L, Fujiwara Y, Orkin SH, Beier DR. Gata4 is necessary for normal pulmonary lobar development. Am J Respir Cell Mol Biol 2007; 36: 391-397.

39 Ackerman KG, Herron BJ, Vargas SO, et al. Fog2 is required for normal diaphragm and lung development in mice and humans. PLoS Genet 2005; 1: 58-65. 